\title{
Dry Sliding Wear Of Intra-Layer Curaua/Basalt Polyester Composites under Varying PV Conditions
}

\author{
T.Premkumar, I. Siva, Sandro C Amico, J.T Winowlin Jappes
}

\begin{abstract}
An investigational analysis was conducted to study the effect of basalt/curaua hybrid composite focusing on wear properties. The hybrid composites are fabricated by resin transfer molding and the tests are conducted by pin on disk as per ASTM G99. Basalt/Curaua relative fiber weight percentage as 0/100,40/60, 60/40, 100/0 are fabricated and analyzed for abrasion wear resistance. Specimens are tested for the load of $50 \mathrm{~N}$ at $1 \mathrm{~m} / \mathrm{s}$ using Pin on Disc wear testing machine by varying abrading distance. Worn out surfaces of the abraded composites are studied by using scanning electron microscopy (SEM) and Fourier- transform infrared spectroscopy (FTIR). Roughness of the worn and pure surfaces is also accounted to measure significance of hybridization on tribological properties of the hybrid composites. Result shows that coefficient of friction is increasing in higher the curaua fiber in hybrid composites. Morphology evident the wear mechanism and internal compatibility of hybrid fibers.
\end{abstract}

Keywords : Basalt fiber, hybrid composite, dry sliding wear, SEM.

\section{INTRODUCTION}

Composite materials are grouping of more than one material that differs from the individual components by their physical and chemical properties. The synthetic fiber (e.g. Basalt, glass, nylon, carbon, Acralic, Modacralic, boron and aramid) or of natural fiber (e.g. Curaua, coconut, hemp, coir, flax, oil palm, banana, sisal, jute, wheat, flax straw, sugarcane, cotton, silk, bamboo). The main advantages of using natural fibers are: less weight, low cost, non- harshness, easy treating, and non-venomousness proved to be good and effective reinforcement $[1,2]$. The tribological performance were tested on pin - on disc sliding wear tester for hybrid composite of coconut sheath and glass fiber reinforced polyester composites were studied, an applied normal load of $40 \mathrm{~N}$ was found at the sliding velocity of

$3.5 \mathrm{~m} / \mathrm{s}$.

Revised Manuscript Received on July 22, 2019.

* Correspondence Author

T.Premkumar, Department of Mechanical Engineering, Kalasalingam Academy of Research and Education, Krishnankoil-626 126, India, Email: t.premkumar@klu.ac.in

I. Siva*, Department of Mechanical Engineering, Kalasalingam Academy of Research and Education, Krishnankoil-626 126, India, Email: isiva@klu.com

Sandro C Amico, Department of Materials Engineering Universidade Federal do Rio Grande do Sul POA/RS, Brazil, Email: amico@ufrgs.br

J.T Winowlin Jappes. Department of Mechanical Engineering, Kalasalingam Academy of Research and Education, Krishnankoil-626 126, India, Email: winowlin@klu.ac.in
The result shows wear resistance is depending on the wt $\%$ of the composites [3]. Compare to other natural fiber for example: Curaua fiber mechanical property are better

than the conventional natural fiber such as sisal or jute The price of the curaua fiber is equal to other natural fibers but curaua is considered odorless as to differ from some other fibers [5]. wear is mostly affect the solid surface, generally involving progressive loss of material, due to relative motion between the substances and surface [4]. In the conclusion of synthetic fiber and natural fiber reinforced polyester composites with dissimilar overall fiber volume fraction and curaua/glass fiber ratio on their mechanical properties [6]. Wear and frictional characteristics are taken in 3 dissimilar environments (a) Dry sliding (b) Oil- lubricated sliding and (c) Sliding in inert gas (argon) for glass fibre reinforced polymer composites are investigated. For this investigation the result show maximum coefficient of friction is attend for argon gas environments because the fibres are easy separation. If separation of fibres are proved by FESEM [7]. In this experiment mass loss and specific wear rate are investigated between Kenaf Polyester Composite (KPEC) and Kenaf Epoxy Composite (KEC). The wear tests are carried by abrasion resistance tester in dry sliding condition at constant velocity of $1.4 \mathrm{~m} / \mathrm{s}$ the test was conducted at room temperature at an applied load of

$30 \mathrm{~N}$. The test result shows at certain distance the specific wear rate is identical for both composite [8]. In this research tribological behaviors are compare the polyetheretherketone and short glass fiber at a weight percentage of 30 . The wear behavior is evaluated on a ball on disc at room temperature. Here we compare the wear and friction for the above composite. The result indicates both wear and friction are increase[9].operating parameters and filler loading are strongly influenced in wear property. Here a natural fibre curaua and a synthetic fibre basalt are mixed with various proportions and as such are tested for a new alternative. This combination extremely different from the other usual conventional combinations has proved comparably advantageous results Ease of Use 


\section{EXPERIMENTAL DETAILS}

\section{A. Materials}

Imported Brazilian curaua and the locally available basalt fibre are used as reinforcement with an unsaturated Isopthalic polyester resin which is considered as a matrix. Methyl Ethyl Ketone Peroxide (MEKP) acts as catalyst andCobalt Napthenate as an accelerator were used.

\section{B. Fabrication of Composites}

The fibres were taken and are combed perfectly to remove the dirt from the fibre surface. Then the dirt free fibres were cut to $12 \mathrm{~mm}$ length. Similarly, basalt fibres are also cut in to $12 \mathrm{~mm}$ length. Then the fibres were placed in the mould cavity of 300mmx300mmx3mm. Resin transfer moulding technique was carried out for the fabrication of the composites. The compressed air was injected to the pressure vessel at 1.5 bar and the resin was transferred to the mould cavity from the pressure vessel. The composites were allowed to cure for $4 \mathrm{hrs}$. The prepared composites were cut to the ASTM standards and a tribological test was carried out

\section{Test Details}

As per the ASTM G-99 standard we conducted the specific wear and coefficient of friction on the pin on -disc. The room temperature was approximately $250 \mathrm{C}$, and the relative humidity was $50 \pm 5 \%$. As per the standard size we can cut the composite specimen into $10 \mathrm{~mm}$ X $10 \mathrm{~mm}$ X $3 \mathrm{~mm}$ comes in contact with a tough alloy steel disc. The test factors are as follows: the normal load was $50 \mathrm{~N}$, the sliding velocity was $3 \mathrm{~m} / \mathrm{s}$, and the maximum sliding distance was $6000 \mathrm{~m}$ in steps of $2000 \mathrm{~m}$. Before the test was taken both the samples and the disc are cleaned with a cotton cloth.

\section{RESULTS AND DISCUSSION}

\section{A. Coefficient of Friction}

Coefficient of friction and sliding distance are directly proportional. The value of Coefficient of friction on four various proportions in three increasing distances of $2000 \mathrm{~m}$ $4000 \mathrm{~m}$ and $6000 \mathrm{~m}$ is taken into consideration and is denoted in the graph (fig1). Here the value of friction coefficient is less in the case of natural fibre Curaua and high in the case of synthetic fibre Basalt. For the intra-layered with combinations of Curaua 60 and basalt 40 and for another inter layer with a vice versa proportion, the friction coefficient takes a value between the values of Curaua and Basalt. The combination that has high Basalt the friction coefficient takes high value.

If the coefficient of friction is formed very low in the purely natural fibre curaua as shown in Fig 1. Micro-Ploughing resulted due to the larger contact between counter and resin is greatly reduced due to the incorporation of basalt fibers. Intra-adhesion between the basalt fiber and curaua

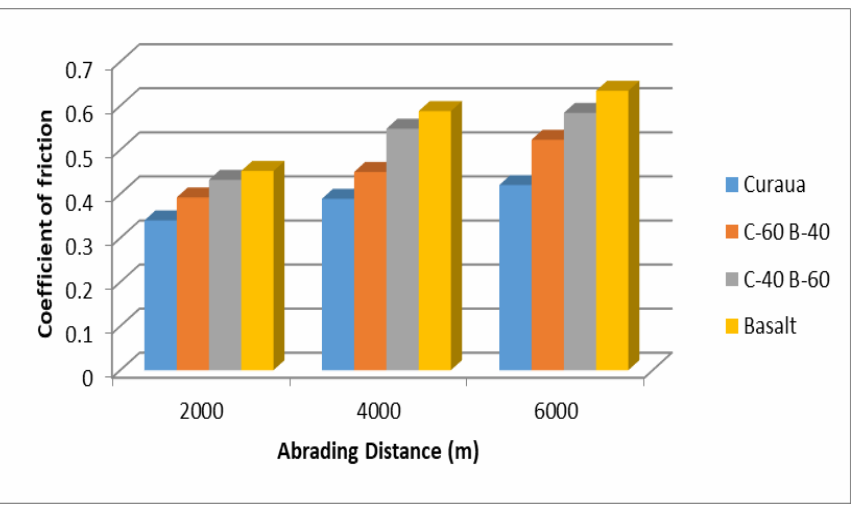

Fig. 1. Coefficient of friction.

\section{B. Specific Rate of Wear}

Specific rate of wear and Distance are inversely proportional. As the distance increases, the specific rate of wear decreases in all the cases. The specific rate of wear is high in the case of natural fibre Curaua and is less in the case of synthetic fibre Basalt. For the inter layer with combinations of Curaua 60 and basalt 40 and for another intra-layered with a vice versa proportion, takes a value between the values of Curaua and Basalt. Higher the amount of Curaua the composite material takes values close to Curaua. As the distance increases the specific rate of wear for the Curaua takes values close to Basalt (Fig 2). But the values of the composite material lie above the value of Curaua.

If the specific rate of wear is formed very high in the purely synthetic fibre basalt as shown in Fig 2. Wear are reduced due to the strong adhesion between the curaua and basalt certain amount of weight are shared by strong fibres.due to that wear rate was reduced in the intra-layered hybrid composites.

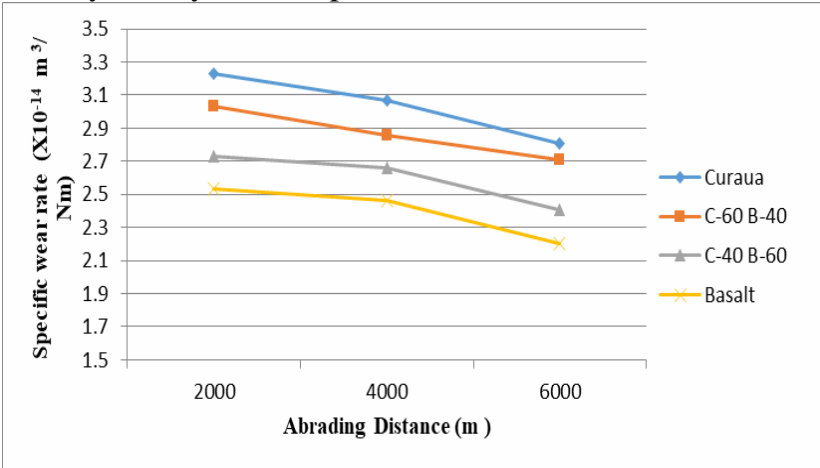

Fig. 2. Specific wear rate.

\section{SEM studies}

Mechanism of friction failure on the composite samples are explored through electron microscopy. Least matrix borders are mainly worn due to the deformation, thinning and interlaminar cracks at subsurface level promoting huge patch removal of matrix. Further matrix worn exposed the contributed fibers to the counter promoting fiber thinning leads fiber fracture. Due to the two actions as synergy the system integrity between the fiber and matrix damaged resulting weaker system. As the hybrid composite is a perfect mix on both parallel and perpendicular sides, the wear

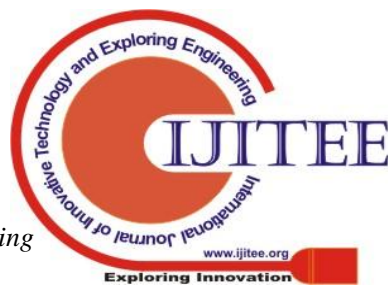


resistance and strength is higher than that of the usual composite mixes of simultaneous sides. Hence composite wall failure modes such as fiber fracture, fiber removal and many other are not possible due to the presence of fiber in both the sides.

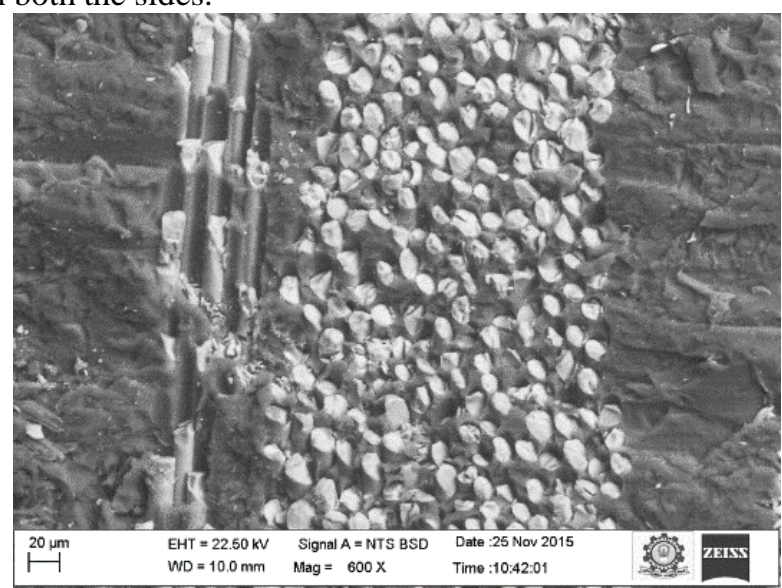

Fig. 3. Surface morphology of untreated fibers reinforced.

\section{CONCLUSIONS}

The tribological property of the natural fiber curaua, the synthetic fiber basalt, an intra-layered combination of Curaua 60 and basalt 40 and another inter layer vice versa proportion have been investigated. The following conclusions could be drawn:

D The hybrid composites tested at the normal and combined proportions shows high wear resistance and low coefficient of friction at various sliding distances, especially at $6,000 \mathrm{~m}$ sliding distance The testing parameters including the sliding distance and many other plays a vital role since the tribological performances strongly depend on these parameters.

$>$ The proportion of natural fibre curaua is more than the specific wear rate is also increased.

$>$ The SEM studies reveal the ratio of mixture in the hybrid composites are purely regular and uniform.

\section{REFERENCES}

1) S.Taj, M.AMunawar, \& S.Khan, Natural fiber-reinforced polymer composites. Proceedings-Pakistan Academy of Sciences,2007, 129.

2) D.N.Saheb, \& J.P.Jog, Natural fiber polymer composites: a review. Advances in polymer technology1999,351-363.

3) I.Siva, J.T.W Jappes, \& B.Suresha, Erratum, Investigation on mechanical and tribological behavior of naturally woven coconu sheath-reinforced polymer composites. Polymer Composites, 2015.

4) I.M.Hutchings, Tribology: friction and wear of engineering materials. Mater. Des, 1992,187.

5) P.Wambua, J.Ivens, \& I.Verpoest, Natural fibres: can they replace glass in fibre reinforced plastics?. composites science and technology 2003,1259-1264.

6) J.H.S.A.Júnior, H.L.O.Júnior, S.C.Amico, \& F.D.R.Amado, Study of hybrid intralaminate curaua/glass composites. Materials \& Design,2012, 111-117.

7) S.Agrawal, K.K.Singh, \& P.K.A.Sarkar, comparative study of wear and friction characteristics of glass fibre reinforced epoxy resin, sliding under dry, oil-lubricated and inert gas environments. Tribology International, 2016,217-224.

8) N.A Nordin, N. A, F.M.Yussof,S. Kasolang, Z.Salleh, \& M.A.Ahmad, Wear Rate of Natural Fibre: Long Kenaf Composite. Procedia Engineering, 2013,145-151.

9) E.Z.Li, W.L.Guo, H.D.Wang, B.S.Xu, \& X.T.Liu, . Research on tribological behavior of PEEK and glass fiber reinforced PEEK composite. Physics Procedia, 2013,453-460.

10) S.Ojha, S.K.Acharya, \& R.Gujjala, Characterization and wear behavior of carbon black filled polymer composites. Procedia Materials Science, 2014,468-475

\section{AUTHORS PROFILE}

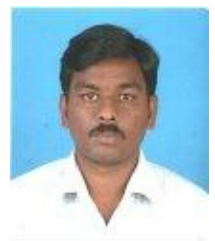

Mr. T. Premkumar is currently working as Assistant Professor in the Department of Mechanical Engineering, Kalasalingam Academy of Research and Education, Anand nagar, Krishnankoil-626126,India He has 6 years teaching as well as research experience

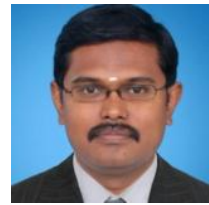

Dr. I. Siva is currently working as Professor in the Department of Mechanical Engineering, Kalasalingam Academy of Research and Education, Anand nagar, Krishnankoil-626126, India He has 15 years teaching as well as research experience. He is a reviewer more than 50 reputed journals $\mathrm{He}$ is a Member of Indian Society for Technical Education. His area of interest are polymer composite, materials characterization, tribology,FML

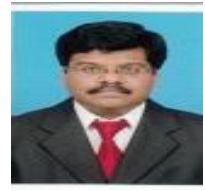

Dr. J.T. Winowlin Jappes is currently working as Professor in the Department of Mechanical Engineering, Kalasalingam Academy of Research and Education, Anand nagar, Krishnankoil-626126, India $\mathrm{He}$ has 15 years teaching as well as research experience. $\mathrm{He}$ is a reviewer more than 10 reputed journal. He has published more than 100 international journals. He is a Member of Indian Society for Technical Education. His area of interests are polymer composite, materials characterization, tribology,FML

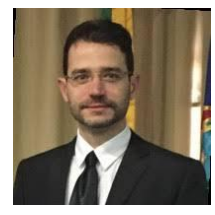

Dr Sandro Amico is currently working as Professor in the Department of Materials Engineering Universidade Federal do Rio Grande do Sul POA/RS Brazil, He has more than 15 years teaching as well as research experience. He is a reviewer more than 20 reputed journals. He has published more than 400 international journals. His area of interests are polymer composite, materials characterization, tribology. 